\title{
Editorial
}

\section{Lebensqualität am Arbeitsplatz und im Wohnbereich}

\section{E. Grandjean ${ }^{I}$}

«Lebensqualität» ist ein Wort, das erst seit einigen Jahren in Umlauf gekommen ist; es bekam seine Bedeutung im Zusammenhang mit den Problemen der Umwelt und der Konsumgesellschaft. Die zweite Hälfte des 20. Jahrhunderts ist in den Industrieländern durch einen starken Anstieg des in Geldwert gemessenen Wohlstandes gekennzeichnet. Damit ist nicht etwa Dankbarkeit und Genügsamkeit, sondern vielmehr Profitsucht und ein Streben nach mehr Luxus, nach mehr Komfort und nach mehr Vergnügungen verbunden. Also ein Streben nach Quantität und nicht nach Qualität. Aus diesem Gedankengut heraus entstand der Begriff «Lebensqualität».

Die physische, die psychische und die kulturelle Güte des Lebens wird mit dem Wort «Lebensqualität» bezeichnet.

Die so verstandene Lebensqualität ist in vielen Bereichen des menschlichen Lebens von Bedeutung; die Sammlung der Arbeiten des vorliegenden Sonderheftes zeigen an einigen Beispielen die Vielfalt der möglichen Einschränkungen von Lebensqualität im Arbeits- und im Wohnbereich. Eine allgemeine Richtlinie lässt sich aus der Gesamtheit der Beiträge ableiten: Arbeits- und Wohnbedingungen müssen den physiologischen, den psychischen und den sozialen Bedürfnissen angepasst sein; dies ist die Voraussetzung für den Schutz und die Förderung von Gesundheit und Wohlbefinden des Menschen.

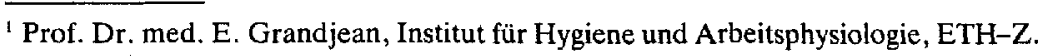

